Published in final edited form as:

Curr Opin HIV AIDS. 2017 January ; 12(1): 69-76. doi:10.1097/COH.0000000000000332.

\title{
Malignancies in Women with HIV Infection
}

\author{
Nora T. Oliver ${ }^{1}$ and Elizabeth Y. Chiao ${ }^{2}$ \\ ${ }^{1}$ Department of Medicine, Section of Infectious Diseases, Atlanta VA Medical Center, Decatur, GA \\ 2Department of Medicine, Section of Infectious Diseases and Health Services Research, Baylor \\ College of Medicine, Houston, TX
}

\begin{abstract}
Purpose of Review-To review current knowledge of different cancer states affecting women with HIV infection.
\end{abstract}

Recent Findings-With improved survival of persons with HIV in the post-cART era, the landscape of malignancies in this population has greatly changed with fewer AIDS-defining malignancies (ADM) and a growing number of non-AIDS defining malignancies (NADM). Women, however, continue to represent a vulnerable population at risk for certain ADM and NADM such as cervical, anal, and breast cancer. Human papilloma virus-mediated cancers disproportionately burden women in resource-poor settings such as Subsaharan Africa. For cancers such as Kaposi's Sarcoma, lung cancer, liver cancer, and colorectal cancer, women share a lower burden of disease compared to their male counterparts. However, there remains a dearth of evidence characterizing these disease states specifically among women.

Summary-Cancer in women with HIV continues to be a major source of morbidity and mortality worldwide, especially in low-income countries. Screening strategies, primary prevention through vaccination against human papillomavirus and viral hepatitis, and treatment for HIV with combined antiviral therapy remain cornerstones in cancer prevention.

\section{Keywords}

women; HIV; cancer; cervical cancer; breast cancer; human papillomavirus

\section{Introduction}

With the aging of the population of HIV-infected individuals due to combined antiretroviral therapy (cART), the landscape of malignancies has shifted. Classical AIDS-defining malignancies (ADM) have decreased; however, other non-AIDS-defining malignancies (NADMs) such as anal, lung, colorectal, and liver cancers continue to pose a significant health threat to patients with HIV [1,2]. Women with HIV continue to be affected by

Corresponding Author: Elizabeth Y. Chiao, MD MPH, Michael E. DeBakey VA Medical Center, HSR\&D Center of Innovation (152), 2002 Holcombe Boulevard, Houston, TX 77030, echiao@ bcm.edu, p: 713-791-1414 ext. 10356.

Disclaimer: The views expressed in this article are those of the author(s) and do not necessarily represent the views of the Department of Veterans Affairs.

Conflicts of Interest

Neither author has any conflicts of interest to declare. 
gynecological and non-gynecological cancers at alarming rates. Cervical cancer, caused by human papillomavirus (HPV) continues to cause a significant burden of cancer and cancerrelated deaths especially in resource limited setting such as Subsaharan Africa (SSA) [3]. Anal cancer has historically been a focus for men with HIV, especially those who have sex with men. However, anal cancer, another HPV-mediated state, has increasingly been recognized as a major health threat to women [4].

Herein, we review the following malignancies currently affecting women with HIV: cervical cancer, anal cancer, breast cancer, ovarian and uterine cancer, lung cancer, non-Hodgkin lymphoma (NHL), and Kaposi's sarcoma (KS). Available research of colorectal and liver cancer indicates that HIV-infected women are less affected by these malignancies compared to HIV-infected men, and will not be included in detail in this review [5-8].

\section{Cervical Cancer}

Among reproductive malignancies, invasive cervical cancer (ICC) is the number one cause of new cancers in women and responsible for the most deaths in women world-wide [3]. Women residing in resource-limited settings bear the brunt of this disease with incidence rates $>30.2 / 100,000$ population compared to more industrialized nations where incidence rates are much lower, $<7.9 / 100,000$ population [3]. In the US where incidence is relatively low, cervical cancer in HIV-infected women the incidence still remains $66 \%$ higher than women without HIV [9]. However, in some areas of SSA, ICC incidence is much higher, nearly 168/100,000 women on cART [10]. Mortality from ICC has continued to be higher in HIV-infected women than HIV-uninfected women. Although mortality is not statistically significant in resource rich settings, [2] women living in resource-limited setting, suffer disproportionate mortality. For instance, in SSA mortality is $>17.5 / 100,000$ population, over 3 -fold the morality of cervical cancer in the US [3].

HIV-infected women are known to be at high risk for human papillomavirus (HPV) infection, the virus responsible for genital warts, pre-cancerous lesions and ICC [11]. Globally, infection with one or multiple types of HPV virus, including high-risk HPV (hrHPV) strains, in HIV-infected women is common and as high as $91 \%$ in some SSA regions $[12,13]$. In SSA, the six most common types of HPV are oncogenic types 16, 18, $35,45,33$, and 52 [14]. Immunologic and virologic HIV control are significant co-factors in the persistence, and progression of HPV infection to pre-malignant lesions and ICC [11, 15, 16]. The use of cART, however, may not completely reverse the oncogenic potential of HPV especially if early malignant changes begin to take place while CD4 counts are low [15].

Clinical presentation of ICC in women with HIV often occurs at younger ages, up to 15 years earlier in advanced HIV compared to HIV-uninfected women [17, 18], which may suggest a shorter latency period in HIV-infected women. Some studies have described women with HIV presenting with later, more advanced stage ICC than HIV-uninfected women [17]; however, other studies have found high rates of advanced ICC in both HIVinfected and HIV-uninfected populations alike in resource limited settings [19], suggesting the pervasive lack of cervical cancer screening. 
Cervical cancer histology is most commonly squamous cell carcinoma (SCC), and treatment includes surgery, chemotherapy, and/or radiation $[17,19]$. Treatment is challenging in many resource limited countries lacking appropriate facilities and equipment [20].. Treatment interruptions and incomplete cancer therapy have significant affects upon cancer outcomes, and women with HIV infection are at high risk of having residual tumor burden [18]. Interestingly, women treated with cART have higher likelihood of treatment completion [19], likely owing to improved treatment tolerance.

Screening for cervical cancer is a key component of primary care for women with HIV. However, wide spread cytology screening and hrHPV detection in low-income countries is difficult to implement due to lack of adequate facilities, resources, finances, and trained personnel, however [21]. The World Health Organization (WHO) has adopted an alternative approach using the "screen-and-treat" method for resource-limited settings. This encourages use of available screening methods, preferably HPV testing as first line, followed by immediate treatments (e.g. cryotherapy) for cervical abnormalities [22]. HPV testing in lowresource, high burden settings may be desirable because of its sensitivity for detecting precancerous lesions as well as its convenience for self-testing [23, 24]; however, costeffectiveness may preclude its widespread use [10].

Cervical cancer is a now a vaccine preventable disease. Widespread vaccination for HPV is critical in young girls and women with HIV in low-income and high-income settings alike. Most recently the 9-valent vaccine, containing a broader coverage of cancer-causing strains (additional types 31, 33, 35, 52, 58), was added to the armamentarium [25]. These are recommended for routine vaccination of females ages 11-26 years [26, 27]. Immunogenicity of the quadrivalent and bivalent vaccines in women with HIV but without evidence of HPV infection is good (>75\%); however, like other vaccines in HIV-infected persons, robust CD4 counts confer better seroconversion response [28]. In 2014 only 58 countries had incorporated HPV vaccination into national immunization campaigns and mostly in highincome settings [27]. More recently, countries in SSA have begun to implement HPV vaccination nationwide with support from global health programs [29], which may have significant cost efficacy [30]. Unfortunately, the details of real-world vaccination uptake in HIV-infected girls and women remain difficult to accomplish [31].

\section{Anal Cancer}

The majority of anal cancers are composed of SCC and associated with the presence of hrHPV types in $90 \%$ of cases [32]. Incidence of anal SCC has continued to increase globally, and in developed countries incidence has increased 1-3\% annually [32]. In the US, women are affected more than men with a rate of 1.8 versus $1.1 / 100,000$ population [33]. Incidence of anal cancer in HIV-infected women in higher income countries is also high (3.9-30 per 100,000) [4]. Women with AIDS, in particular, have a nearly 15 -fold higher risk of developing invasive anal SCC compared to the general population (SIR 14.5; 95\% CI, 8.8-22.4) [34]. Risk factors for anal infection with HPV include tobacco use, perianal warts, and presence of cervical HPV infection [4]. 
Poor immune status with CD4 $<200$ cells $/ \mu \mathrm{L}$ is a risk factor for anal HPV infection [4]; moreover, increased risk of HPV-associated neoplasia has been associated with increased duration after AIDS diagnosis [34, 35]. Immunosuppression may facilitate early viralmediated oncogenesis which is irreversible despite CART-mediated immune restoration [34]. Interestingly, HIV viral load has not been associated with the presence of abnormal anal cytologic findings in HIV-infected women [4], but has been associated with an increased number of high-grade squamous intraepithelial lesions and anal condyloma [36, 37].

Practice of anal cancer screening using anal canal Dacron swab technique and liquid cytological evaluation has derived from cervical cytology testing. Classifying cellular histology of anal lesions also employs the revised Bethesda System for Reporting Cervical Cytology [38, 39]. Sensitivity of detecting high-grade anal neoplasia ranges from 69-93\% in several studies [38], and abnormal anal cytology should be further investigated with high resolution anoscopy (HRA), which is analogous to the cervical colposcopy [40, 41]. HPV DNA testing is controversial given the high prevalence of hrHPV viral infection in HIVinfected persons [39, 42]. However, presence of hrHPV genotype 16 is associated with concurrent high-grade anal lesions in women with HIV [43, 44].

Due to lack of standardized guidelines on anal cancer screening, clinicians have been charged with creating local protocols to address this need. Determining which women are at high risk for anal cancer is of the utmost importance. Women with a history of cervical or vulvar neoplasias are more likely to have anal HPV-infection and abnormal anal cytology [4, $43,45]$. The presence of anal warts or condyloma acuminata may also be an indicator for HPV infection of the anal canal and may warrant further screening. A limitation of implementing anal cancer screening beyond a yearly digital rectal exam is the lack of readily accessible and trained personnel and equipment for performing HRA. If HRA is not available, anal cytology is discouraged [46].

Primary prevention of anal cancer has been more extensively studied in men due to high the high incidence rates of anal cancer in men who have sex with men (MSM). Women receiving the latest 9-valent HPV vaccine could potentially reap significant benefit and reduction of up to $87 \%$ of anogenital cancers globally [47]. Anal cancer prevention is an added benefit of early HPV vaccination in girls and women with HIV or in areas with highendemic rates of HIV and HPV infection.

\section{Breast Cancer}

Breast cancer remains the most common cancer type (23\% of total new cancer cases) in women living in industrialized and non-industrialized countries [3]. It also is the most common cause of cancer-related deaths among women, accounting for $15 \%$ of total cancer deaths [3]. Breast cancer has previously been described as occurring less frequently in women with AIDS compared to the general population [48-50]. One large retrospective US study of women with AIDS followed for 665,987 pys showed a SIR 0.69 (95\% CI, 0.62 0.77); however, increases over the follow-up period of locally/regionally-disseminated disease approached that of the general population [51]. 
As HIV-infected women age, the incidence of breast cancer is likely going to increase.

Previous case series have demonstrated that women present at younger ages, frequently with advanced disease, increased multifocality of disease, early metastasis, and poor outcomes [52-54]. Prior studies have not demonstrated significant association with low CD4 counts or AIDS diagnoses with the development of breast cancer [54]. The links between HIV, the immune response, and natural history of breast cancer are unclear based on the limited, available data. Larger studies are needed to identify HIV-specific risk factors in the acquisition and progression of breast cancer.

Breast cancer treatment in HIV-infected women remains challenging because chemotherapeutic agents can also pose significant drug interactions with anti-retroviral therapies. Standard guideline-based therapies based on stage at diagnosis should be implemented for eligible HIV-infected women[54]. Rates of estrogen, progesterone, or HER-2/neu receptor status of breast tumors in HIV-infected women are not well established, but estrogen-receptor positivity has been reported in nearly $50 \%$ of cases [54, 55]. Close attention should be paid to drug interactions between breast cancer therapies, including hormonal therapies and antiretroviral therapies. Cancer-specific mortality in women with HIV in the post-cART era remains higher than in the general population (HR 3.43, 95\% CI, 2.35-5.01) [2]. In one case series, progression free-survival at 5 years was $50 \%$ and median overall survival was 52 months [54, 55].

Screening and prevention of breast cancer are of the utmost importance in women with HIV infection. Current US Preventive Service Task Force (USPSTF) screening guidelines recommend for the general population biennial mammography for women ages 50-74; however, more frequent screening can be used in patients who may be at increased risk [56]. For HIV-infected women, this level of screening is the acceptable practice [57] until further risk factors (e.g. HIV-specific or genetic markers) beyond family history can be firmly established and in practice to better identify women at high risk for breast cancer. Despite these recommendations, screening for breast cancer in women with HIV remains challenging with historically low screening rates (30-50\%) compared to the general population $[58,59]$.

\section{Ovarian and Uterine Cancer}

Uterine and ovarian cancers account for about $4 \%$ of new cancer diagnoses in women [60, 61]. While relatively less common, ovarian malignancies are responsible for are large burden of annual deaths (age-standardized rate 3.8\%) with poor survival often less than $50 \%$ when compared to other gynecological cancers $[3,60]$.

Only few studies have characterized ovarian and uterine cancers in women with HIV infection. Interestingly, one large study following 85,268 women for 665,987 pys found significantly lower incidence of uterine cancer compared to the general population with only 31 cases (SIR 0.57; 95\% CI 0.39-0.81) [51]. After stratifying groups based on menopausal status, women $<50$ years had a uterine cancer SIR 0.86 (05\% CI, 0.54-1.32), and women $>50$ years had a SIR of 0.33 (95\% CI, $0.4-1.68$ ). Within this same study only 42 cases of ovarian cancer were identified (SIR 1.05; 95\% CI, 0.75-1.42) [51]. With regard to immune 
status, there was also no significant relationship between onset of AIDS diagnosis or CD4 count for uterine or ovarian cancer. However, infertility and poor ovarian function are also more common in women with HIV than in the general population [62]; thus, the impact of HIV infection upon ovarian cancer development is unclear.

Data on mortality due to ovarian and uterine cancers specifically in the HIV population is limited likely due to the relative infrequency of these cancers. One Italian study, mortality from uterine cancer accounted for 4\% of cancer-specific deaths from 2006-2011 [63]. Standardized mortality ratio of women with AIDS and uterine cancer was 52.5 (95\% CI, 14.3-134.5) compared to those without AIDS in the same study [63].

\section{Lung Cancer}

Lung cancer, primarily non-small cell lung cancer (NSCLC), is a leading cause of cancer death among persons with HIV infection and poses a major threat to morbidity and mortality in the HIV population globally $[2,63]$. Over time from the pre-cART era to post-cART, the number of lung cancer cases has risen more than 2-fold in the US, especially in people $>50$ years, which is likely due to both high rates of tobacco use and aging in the HIV-infected population [64]. Even after carefully controlling for smoking prevalence, HIV itself has been described as an independent risk factor for lung cancer [65], and women with HIV have nearly 4-fold higher incidence than the general population [66]. Recurrent bacterial pneumonias among persons with HIV also has been implicated as a risk factor for lung cancer development due to persistent tissue inflammation [67]. Mortality continues to remain higher among patients with HIV in the post-cART era compared to HIV-uninfected patients (HR 1.38, 95\% CI 1.21-1.56) [2].

Lung cancer patients with HIV tend to present at younger ages ( $54.1 \mathrm{v} 60.5$ years) compared to those without HIV, and a South African study found no statistical gender difference between HIV-infected and uninfected lung cancer cases [68, 69]. Several studies have found that HIV-infected patients commonly present with advanced disease (stage III/IV) [65, 6870]. In addition, HIV-infected patients with NSCLC have worse 5-year overall survival compared to those without HIV (9\% versus 23\%) [71]. Robust CD4 count (>200 cells $/ \mu \mathrm{L}$ ) carry improved survival compared to those with low CD4 counts (median survival 11.5 months compared to 3.4 months) [69].

Tobacco smoking prevalence among HIV-infected men and women is significant with rates nearly $2-3$ times higher than in the general population [72, 73]. Among persons with HIV and lung cancer, current smokers (aIRR 6.3, 95\% CI, 4.7-8.4) and former smokers (aIRR 3, 95\% CI 2.2-4.1) have higher risk of lung cancer than never smokers [65]. Tobacco smoking cessation should be a key component of primary care and for lung cancer prevention for HIV-infected women, pharmacologic-aides may be useful during cessation attempts [74].

Because of improved mortality benefit, lung cancer screening with low-dose computed tomography (LDCT) is recommended for people aged 55-80 in the general population with at least a 30 pack-year smoking history and currently smoke or who have quit within 15 years, regardless of gender [75]. Some caution must be taken in screening HIV-infected 
patients, especially those with poor CD4 count, as they are likely to have false positive LDCT findings due to prior lung infections [76]. These may lead to unnecessary testing, surgery, and patient anxiety.

\section{Non-Hodgkin Lymphoma}

The post-cART era has experienced an overall decline in incidence of NHL; however, incidence of NHL among HIV-infected persons continues to be significantly higher (>10fold) than the general population $[1,77]$. Gender-specific incidence rates of NHL favor women, who have a lower incidence of this malignancy across high and low-income regions. French and Swiss data have shown fewer HIV-infected women are at risk of acquiring NHL compared to HIV-infected men (16\% v 18\%, respectively) [5, 66]. In Southeast Asia, North Africa, and SSA, NHL affects women less than men as well. [77].

NHL remains the largest cause death among the ADMs [2, 63, 78]; however, NHL-specific death in the post-cART era affects women much less frequently than men (3-22\% versus $15.2-78 \%$, respectively) [78, 79]. Furthermore, with the widespread implementation of cART, 5-year survival across genders has improved dramatically compared to pre-cART eras in France (65\% v 15\% 5-year survival, respectively) and in the US (54\% to 9\% 5-year, respectively) [5, 79]. In addition, increased uptake of standard, more dose-intensive chemotherapeutic treatment strategies has helped improve complete remission and survival rates in the HIV-infected population regardless of low CD4 counts and AIDS diagnoses [80, $81]$.

\section{Kaposi's Sarcoma}

Human herpesvirus-8 (HHV-8) infection has a significant geographic variance ranging from $1-8 \%$ in Western nations and 40-80\% in SSA [82]. People with HIV infection are more likely (OR 1.99, 95\% CI, 1.7-2.34) to have HHV-8 infection than the general population [83]. This parallels the trends of AIDS-related KS, and in the US, for example, the incidence of KS within the HIV population is exceedingly high compared to the general population (130/100,000 py versus $0.2 / 100,000$ py, respectively) [1]. HIV-infected men carry the largest burden of these conditions among persons with HIV due to the high prevalence of HHV-8 infection among MSM [84]. A recent systematic review comparing HHV-8 prevalence between men and women found that after excluding studies with MSM, heterosexual men in SSA had a increased risk of HHV-8 infection (OR 1.21, 95\% confidence interval (CI) 1.091.34), but this was not true for men from other localities [85]. In resource-rich countries, KS represents a small fraction (2-3\%) of all ADM in women [5, 86, 87]; however, in lowincome regions such as SSA, incidence of KS in women with HIV seems to be elevated, especially in untreated groups $(1,214 / 100,000$ py) [88].

Comprehensive data on clinical presentation of KS in women are limited; however, women may present at younger ages (second and third decades) and may have more disseminated skin disease compared to men $[89,90]$. Treatment of HIV with cART is the cornerstone of prevention and treatment of KS owing to improved immunological control [91]. 
Additionally, systemic chemotherapeutic agents such as taxanes and anthracyclines for progressive KS may be beneficial [92].

Survival data in women compared to men is mixed in studies from SSA regions.

Furthermore, treatment outcomes specifically for HIV-infected women are limited likely due to lower burden of disease in this gender class, especially in Western regions. In one small study from Uganda, sex was not a risk factor for KS-associated mortality [93]. However, another study from South Africa found women were twice as likely to die from KS compared to their male counterparts [88].

\section{Key Points}

- $\quad$ Cervical cancer disproportionately affects women with HIV likely due to high prevalence and persistence of HPV infection.

- Lack of primary prevention programs, screening infrastructure, and treatment resources have contributed to high mortality in low-income countries.

- HPV vaccination has been shown to be beneficial and cost-effective in preventing cervical and anal cancer in women.

- $\quad$ Treating underlying HIV with cART is a critical component of cancer prevention, treatment, and survival for HIV-infected women with cancer.

\section{Conclusion}

At the cornerstone of all prevention strategies for cancer in HIV-infected women is engagement in healthcare and effective treatment with cART. Cancer prevention is critical to curb morbidity and mortality in HIV-infected women, especially because many neoplastic states present at younger ages and at more advanced stages than in the general population. In addition, HIV-infected women are especially at risk for HPV-mediated disease due to persistent HPV infection, especially in low-income settings with high HPV infection prevalence. Thus, primary prevention with vaccination strategies for HPV-related neoplasias is of utmost importance. Furthermore, implementation, access, and affordability of breast and lung cancer screening are also key components for decreasing cancer morbidity and mortality among HIV-infected women. Finally, differences in the incidence and mortality of non-female specific cancers, such as: colorectal, liver, KS, and lymphoma are needed to better clarify the potential effect of gender specific differences, including sex hormones and other gender specific biologic and behavioral risk factors on the incidence and outcomes of these cancers in HIV-infected women.

\section{Acknowledgments}

Nora T. Oliver was the primary author of the manuscript. Elizabeth Y. Chiao provided content, writing and editorial supervision.

Disclosures: Dr. Elizabeth Chiao received research funding for this project through a 2011 developmental grant from the Baylor-UT Houston Center for AIDS Research (CFAR), a NIH-funded program (NIH P30 CA125123), the AIDS Malignancy Consortium (NIH 2U01CA121947), and NIH R01 CA163103. This work was also supported in part by the Center for Innovations in Quality, Effectiveness and Safety (\#CIN 13-413). 


\section{Reference and recommended reading}

Papers of particular interest, published within the period of review have been highlighted as:

* of special interest

** of outstanding interest

1*. Silverberg MJ, Lau B, Achenbach CJ, et al. Cumulative Incidence of Cancer Among Persons With HIV in North America: A Cohort Study. Ann Intern Med. 2015; 163(7):507-18. This wellexecuted large observational study describes cumulative risk using a competing risk approach of many ADMs and NADMs in HIV-positive persons compared to HIV-negative persons the US and Canada from 1996-2009. While mortality drecreased overtime for persons with HIV, mortality rate and cancer indicence for KS, anal cancer, and NHL remain higher in the HIV population compared to their negative counterparts. [PubMed: 26436616]

2. Coghill AE, Shiels MS, Suneja G, Engels EA. Elevated Cancer-Specific Mortality Among HIVInfected Patients in the United States. J Clin Oncol. 2015; 33(21):2376-83. [PubMed: 26077242]

3. Ferlay, J., Soerjomataram, I., Ervik, M., et al. GLOBOCAN 2012 v1.0, Cancer Incidence and Mortality Worldwide: IARC CancerBase No. 11 [Internet]. Lyon, France: International Agency for Research on Cancer; 2013. Available from: http://globocan.iarc.fr [accessed on 18 July 2016]

4**. Stier EA, Sebring MC, Mendez AE, et al. Prevalence of anal human papillomavirus infection and anal HPV-related disorders in women: a systematic review. Am J Obstet Gynecol. 2015; 213(3): 278-309. This very intersting systematic review brings to the forefront the burden of disease and changing epidemiology of HPV infection and its malignant sequelae in women with and without HIV infection. Women with HIV and prior cervical lesions are at high risk for developing anal HPV infection and neoplasia. [PubMed: 25797230]

5. Hleyhel M, Belot A, Bouvier AM, et al. Trends in survival after cancer diagnosis among HIVinfected individuals between 1992 and 2009. Results from the FHDH-ANRS CO4 cohort. Int J Cancer. 2015; 137(10):2443-53. [PubMed: 25976897]

6. Westbrook ML, Garg S, Chapman S, et al. Hepatocellular carcinoma in HIV-infected women: two case reports. R I Med J. 2013; 96(1):21-4.

7. Sigel C, Cavalcanti MS, Daniel T, et al. Clinicopathologic Features of Colorectal Carcinoma in HIVPositive Patients. Cancer Epidemiol Biomarkers Prev. 2016; 25(7):1098-104. [PubMed: 27197294]

8. Gahagan JV, Halabi WJ, Nguyen VQ, et al. Colorectal Surgery in Patients with HIV and AIDS: Trends and Outcomes over a 10-Year Period in the USA. J Gastrointest Surg. 2016; 20(6):1239-46. [PubMed: 26940943]

9. Brickman C, Palefsky JM. Human papillomavirus in the HIV-infected host: epidemiology and pathogenesis in the antiretroviral era. Curr HIV/AIDS Re. 2015; 12(1):6-15.

10. Lince-Deroche N, Phiri J, Mchelow P, Smith JS, Firnhaber C. Costs and Cost Effectiveness of Three Approaches for Cervical Cancer Screening among HIV-Positive Women in Johannesburg, South Africa. PLoS One. 2015; 10(11):e0141969. [PubMed: 26569487]

11. Strickler HD, Burk RD, Fazzari M, et al. Natural history and possible reactivation of human papillomavirus in human immunodeficiency virus-positive women. J Natl Cancer Inst. 2005; 97(8):577-86. [PubMed: 15840880]

12. Denny LA, Franceschi S, de Sanjose S, et al. Human papillomavirus, human immunodeficiency virus and immunosuppression. Vaccine. 2012; 30(Suppl 5):F168-74. [PubMed: 23199960]

13*. Clifford GM, de Vuyst H, Tenet V, et al. Effect of HIV infection on human papillomavirus types causing invasive cervical cancer in Africa. J Acquir Immune Defic Syndr. 2016 Jun 15. This Africa-focused, comprehensive meta-analysis investigates the types of HPV infection and the relationship of cervical cancer in women with and without HIV infection. Women with HIV are significantly at higher risk for ICC compared to women without HIV. and HPV types 16/18 are the most prevelant types related to ICC in HIV-positive women.

14. Williamson AL. The Interaction between Human Immunodeficiency Virus and Human Papillomaviruses in Heterosexuals in Africa. J Clin Med. 2015; 4(4):579-92. [PubMed: 26239348] 
15. Clifford GM, Franceschi S, Keiser O, et al. Immunodeficiency and the risk of cervical intraepithelial neoplasia $2 / 3$ and cervical cancer: A nested case-control study in the Swiss HIV cohort study. Int J Cancer. 2016; 138(7):1732-40. [PubMed: 26537763]

16. Oga EA, Brown JP, Brown C, et al. Recurrence of cervical intraepithelial lesions after thermocoagulation in HIV-positive and HIV-negative Nigerian women. BMC Womens Health. 2016; 16(1):25. [PubMed: 27169666]

17. Moodley M, Moodley J, Kleinschmidt I. Invasive cervical cancer and human immunodeficiency virus (HIV) infection: a South African perspective. Int J Gynecol Cancer. 2001; 11(3):194-7. [PubMed: 11437924]

18. Gichangi P, Bwayo J, Estambale B, et al. HIV impact on acute morbidity and pelvic tumor control following radiotherapy for cervical cancer. Gynecol Oncol. 2006; 100(2):405-11. [PubMed: 16274737]

19. Ntekim AO, Campbell O, Rothenbacher D. Optimal management of cervical cancer in HIVpositive patients: a systematic review. Cancer Med. 2015; 4(9):1381-93. [PubMed: 26136407]

20. Datta NR, Samiei M, Bodis S. Radiation therapy infrastructure and human resources in low- and middle-income countries: present status and projections for 2020. Int J Radiat Oncol Biol Phys. 2014; 89(3):448-57. [PubMed: 24751411]

21. Franceschi S, Jaffe H. Cervical cancer screening of women living with HIV infection: a must in the era of antiretroviral therapy. Clin Infect Dis. 2007; 45(4):510-3. [PubMed: 17638204]

22. WHO. [Accessed 17 July 2016] WHO guidelines for screening and treatment of precancerous lesions for cervical cancer prevention. 2013. Available at http://www.who.int/reproductivehealth/ publications/cancers/screening_and_treatment_of_precancerous_lesions/en/

23. Firnhaber C, Mayisela N, Mao L, et al. Validation of cervical cancer screening methods in HIV positive women from Johannesburg South Africa. PLoS One. 2013; 8(1):e53494. [PubMed: 23326441]

24. Zhao FH, Lewkowitz AK, Chen F, et al. Pooled analysis of a self-sampling HPV DNA Test as a cervical cancer primary screening method. J Natl Cancer Inst. 2012; 104(3):178-88. [PubMed: 22271765]

25. Petrosky E, Bocchini JA Jr, Hariri S, et al. Use of 9-valent human papillomavirus (HPV) vaccine: updated HPV vaccination recommendations of the advisory committee on immunization practices. MMWR Morb Mortal Wkly Rep. 2015; 64(11):300-4. [PubMed: 25811679]

26. Markowitz LE, Dunne EF, Saraiya M, et al. Quadrivalent Human Papillomavirus Vaccine: Recommendations of the Advisory Committee on Immunization Practices (ACIP). MMWR Recomm Rep. 2007; 56(RR-2):1-24.

27. WHO. Human papillomavirus vaccines: WHO position paper, October 2014-Recommendations. Vaccine. 2015; 33(36):4383-4. [PubMed: 25510390]

28. Kojic EM, Kang M, Cespedes MS, et al. Immunogenicity and safety of the quadrivalent human papillomavirus vaccine in HIV-1-infected women. Clin Infect Dis. 2014; 59(1):127-35. [PubMed: 24723284]

29. Hanson CM, Eckert L, Bloem P, Cernuschi T. Gavi HPV Programs: Application to Implementation. Vaccines (Basel). 2015; 3(2):408-19. [PubMed: 26343194]

30. Li X, Stander MP, Van Krieking G, Demarteau N. Cost-effectiveness analysis of human papillomavirus vaccination in South Africa accounting for human immunodeficiency virus prevalence. BMC Infect Dis. 2015; 15:566. [PubMed: 26652918]

31. Kojic EM, Rana AI, Cu-Uvin S. Human papillomavirus vaccination in HIV-infected women: need for increased coverage. Expert Rev Vaccines. 2016; 15(1):105-17. [PubMed: 26599305]

32. Grulich AE, et al. The epidemiology of anal cancer. Sex Health. 2012; 9(6):504-8. [PubMed: 22958581]

33. Viens LJ, Henley SJ, Watson M, et al. Human Papillomavirus-Associated Cancers - United States, 2008-2012. MMWR Morb Mortal Wkly Rep. 2016; 65(26):661-6. [PubMed: 27387669]

34. Chaturvedi AK, Madeleine MM, Biggar RJ, Engels EA. Risk of human papillomavirus-associated cancers among persons with AIDS. J Natl Cancer Inst. 2009; 101(16):1120-30. [PubMed: 19648510] 
35. Frisch M, Biggar RJ, Goedert JJ. Human papillomavirus-associated cancers in patients with human immunodeficiency virus infection and acquired immunodeficiency syndrome. J Natl Cancer Inst. 2000; 92(18):1500-10. [PubMed: 10995805]

36. Mullins TL, Wilson CM, Rudy BJ, Sucharew H, Kahn JA. Incident anal human papillomavirus and human papillomavirus-related sequelae in HIV-infected versus HIV-uninfected adolescents in the United States. Sex Transm Dis. 2013; 40(9):715-20. [PubMed: 23949587]

37. Hou JY, Smotkin D, Grossberg R, et al. High prevalence of high grade anal intraepithelial neoplasia in HIV-infected women screened for anal cancer. J Acquir Immune Defic Syndr. 2012; 60(2):169-72. [PubMed: 22466085]

38. Chiao EY, Giordano TP, Palefsky JM, Tyring S, El Serag H. Screening HIV-infected individuals for anal cancer precursor lesions: a systematic review. Clin Infect Dis. 2006; 43(2):223-33. [PubMed: 16779751]

39. Benevolo M, Donà MG, Ravenda PS, Chiocca S. Anal human papillomavirus infection: prevalence, diagnosis and treatment of related lesions. Expert Rev Anti Infect Ther. 2016; 14(5): 465-77. [PubMed: 27050294]

40. Jay N, Bery JM, Hogeboom CJ. Colposcopic appearance of anal squamous intraepithelial lesions: relationship to histopathology. Dis Colon Rectum. 1997; 40(8):919-28. [PubMed: 9269808]

41. Richel O, Hallensleben ND, Kreuter A, et al. High-resolution anoscopy: clinical features of anal intraepithelial neoplasia in HIV-positive men. Dis Colon Rectum. 2013; 56(11):1237-42. [PubMed: 24104998]

42. Berry JM, Palefsky JM, Jay N, et al. Performance characteristics of anal cytology and human papillomavirus testing in patients with high-resolution anoscopy-guided biopsy of high-grade anal intraepithelial neoplasia. Dis Colon Rectum. 2009; 52(2):239-47. [PubMed: 19279418]

43. Heard I, Etienney I, Potard V, et al. High Prevalence of Anal Human Papillomavirus-Associated Cancer Precursors in a Contemporary Cohort of Asymptomatic HIV-Infected Women. Clin Infect Dis. 2015; 60(10):1559-68. [PubMed: 25645213]

44. Heard I, Pizot-Martin I, Potard V, et al. Prevalence of and Risk Factors for Anal Oncogenic Human Papillomavirus Infection Among HIV-Infected Women in France in the Combination Antiretroviral Therapy Era. J Infect Dis. 2016; 213(9):1455-61. [PubMed: 26690345]

45. Cronin B, Bregar A, Luis C, et al. Evaluation of anal cytology and dysplasia in women with a history of lower genital tract dysplasia and malignancy. Gynecol Oncol. 2016; 141:492-496. [PubMed: 27095188]

46. Cronin B, Bregar A, Luis C, et al. Evaluation of anal cytology and dysplasia in women with a history of lower genital tract dysplasia and malignancy. Gynecol Oncol. 2016; 141(3) 492-6.46. DHHS, U. Guidelines for the Prevention and Treatment of Opportunistic Infections in HIVinfected Adults and Adolescents. AIDSinfo.; 2016.

47*. Serrano B, de Sanjose S, Tous S, et al. Human papillomavirus genotype attribution for HPVs 6, $11,16,18,31,33,45,52$ and 58 in female anogenital lesions. Eur J Cancer. 2015; 51(13):173241. [PubMed: 26121913]

48. Goedert JJ, Cote TR, Virgo P, et al. Spectrum of AIDS-associated malignant disorders. Lancet. 1998; 351(9119):1833-9. [PubMed: 9652666]

49. Herida M, Mary-Krause M, Kaphan R, et al. Incidence of non-AIDS-defining cancers before and during the highly active antiretroviral therapy era in a cohort of human immunodeficiency virusinfected patients. J Clin Oncol. 2003; 21(18):3447-53. [PubMed: 12972519]

50. Amir H, Kaaya EE, Kwesigabo G, Kiitinya JN. Breast cancer before and during the AIDS epidemic in women and men: a study of Tanzanian Cancer Registry Data 1968 to 1996. J Natl Med Assoc. 2000; 92(6):301-5. [PubMed: 10918766]

51. Goedert JJ, Schairer C, McNeel TS, et al. Risk of breast, ovary, and uterine corpus cancers among 85,268 women with AIDS. Br J Cancer. 2006; 95(5):642-8. [PubMed: 16868538]

52. Pantanowitz L, Connolly JL. Pathology of the breast associated with HIV/AIDS. Breast J. 2002; 8(4):234-43. [PubMed: 12100117]

53. El-Rayes BF, Berenji K, Schuman P, Philip PA. Breast cancer in women with human immunodeficiency virus infection: implications for diagnosis and therapy. Breast Cancer Res Treat. 2002; 76(2):111-6. [PubMed: 12452447] 
54. Hurley J, Franco S, Gomez-Fernandez C, et al. Breast cancer and human immunodeficiency virus: a report of 20 cases. Clin Breast Cancer. 2001; 2(3):215-20. discussion 221. [PubMed: 11899415]

55. Gomez A, Montero AJ, Hurley J. Clinical outcomes in breast cancer patients with HIV/AIDS: a retrospective study. Breast Cancer Res Treat. 2015; 149(3):781-8. [PubMed: 25663516]

56. Siu A. Screening for Breast Cancer: U.S. Preventive Services Task Force Recommendation Statement. Ann Intern Med. 2016; 64(4):279-297.

57. Sigel K, Dubrow R, Silverberg M, et al. Cancer screening in patients infected with HIV. Curr HIV/ AIDS Rep. 2011; 8(3):142-52. [PubMed: 21695529]

58. Sheth AN, Moore RD, Gebo KA. Provision of general and HIV-specific health maintenance in middle aged and older patients in an urban HIV clinic. AIDS Patient Care STDS. 2006; 20(5): 318-25. [PubMed: 16706706]

59. Weinstein ZM, Battaglia TA, Baranoski AS. Factors Associated with Adherence to Routine Screening Mammography in HIV-Infected Women. J Womens Health (Larchmt). 2016; 25(5):4739. [PubMed: 27168388]

60. Sankaranarayanan R, Ferlay J. Worldwide burden of gynaecological cancer: the size of the problem. Best Pract Res Clin Obstet Gynaeco. 2006; 20(2):207-25.

61. Siegel RL, Miller KD, Jemal A. Cancer statistics, 2016. CA Cancer J Clin. 2016; 66(1):7-30. [PubMed: 26742998]

62. Santulli P, de Villardi D, Gayet V, et al. Decreased ovarian reserve in HIV-infected women. AIDS. 2016; 30(7):1083-8. [PubMed: 27028143]

63. Zucchetto A, Virdone S, Taborelli M, et al. Non-AIDS Defining Cancer Mortality: Emerging Patterns in the Late HAART Era. J Acquir Immune Defic Syndr. 2016

64. Shiels MS, Pfeiffer RM, Gial MH, et al. Cancer burden in the HIV-infected population in the United States. J Natl Cancer Inst. 2011; 103(9):753-62. [PubMed: 21483021]

65. Sigel K, Wisniveski J, Gordon K, et al. HIV as an independent risk factor for incident lung cancer. AIDS. 2012; 26(8):1017-25. [PubMed: 22382152]

66. Clifford GM, Polesel J, Rickenbach M, et al. Cancer risk in the Swiss HIV Cohort Study: associations with immunodeficiency, smoking, and highly active antiretroviral therapy. J Natl Cancer Inst. 2005; 97(6):425-32. [PubMed: 15770006]

67. Shebl FM, Engels EA, Goedert JJ, Chaturvedi AK. Pulmonary infections and risk of lung cancer among persons with AIDS. J Acquir Immune Defic Syndr. 2010; 55(3):375-9. [PubMed: 20736841]

68*. Koegelenberg CF, et al. The impact of HIV infection on the presentation of lung cancer in South Africa. S Afr Med J. 2016; 106(7):666-8. This interesting prospective, observational study from South Africa describes a cohort of lung cancer patients diagnosed with HIV. Patients with HIV and lung cancer tended to be men and younger than their HIV-negative counterparts. They and had more prevelant squamous cell carcinoma, poor performance status, and advanced stage disease as well. [PubMed: 27384354]

69. Hakimian R, Fang H, Thomas L, Edelman MJ. Lung cancer in HIV-infected patients in the era of highly active antiretroviral therapy. J Thorac Oncol. 2007; 2(4):268-72. [PubMed: 17409796]

70. CDC. Human papillomavirus-associated cancers - United States, 2004-2008. MMWR Morb Mortal Wkly Rep. 2012; 61:258-61. [PubMed: 22513527]

71. Sigel K, Crothers K, Dubrow R, et al. Prognosis in HIV-infected patients with non-small cell lung cancer. Br J Cancer. 2013; 109(7):1974-80. [PubMed: 24022194]

72. Tesoriero JM, Gieryic SM, Carrascal A, Lavigne HE. Smoking among HIV positive New Yorkers: prevalence, frequency, and opportunities for cessation. AIDS Behav. 2010; 14(4):824-35. [PubMed: 18777131]

73. Tron L, Lert F, Spire B, Dray-Spira R. Tobacco smoking in HIV-infected versus general population in France: heterogeneity across the various groups of people living with HIV. PLoS One. 2014; 9(9):e107451. [PubMed: 25202968]

74. Shuter J, Pearlman BK, Stanton CA, et al. Gender Differences among Smokers Living with HIV. J Int Assoc Provid AIDS Care. May.2016

75. Moyer VA. Screening for lung cancer: U.S. Preventive Services Task Force recommendation statement. Ann Intern Med. 2014; 160(5):330-8. [PubMed: 24378917] 
76. Sigel K, Wisnivesky J, Shahrir S, et al. Findings in asymptomatic HIV-infected patients undergoing chest computed tomography testing: implications for lung cancer screening. AIDS. 2014; 28(7): 1007-14. [PubMed: 24401647]

77. Chen M, Jen I, Chen YH, et al. Cancer incidence in a Nationwide HIV/AIDS patient cohort in Taiwan in 1998-2009. J Acquir Immune Defic Syndr. 2014; 65(4):463-72. [PubMed: 24583616]

78. Morlat, Roussillon C, Henard S, et al. Causes of death among HIV-infected patients in France in 2010 (national survey): trends since 2000. AIDS. 2014; 28(8):1181-91. [PubMed: 24901259]

79. Howlader N, Shiels MS, Mariotto AB, Engels EA. Contributions of HIV to Non-Hodgkin Lymphoma Mortality Trends in the US. Cancer Epidemiol Biomarkers Prev. Jul.2016

80. Barta SK, Samuel MS, Xue X, et al. Changes in the influence of lymphoma- and HIV-specific factors on outcomes in AIDS-related non-Hodgkin lymphoma. Ann Oncol. 2015; 26(5):958-66. [PubMed: 25632071]

81. Barta SK, Xue X, Wang D, et al. Treatment factors affecting outcomes in HIV-associated nonHodgkin lymphomas: a pooled analysis of 1546 patients. Blood. 2013; 122(19):3251-62. [PubMed: 24014242]

82. Phipps W, Saracino M, Selke S, et al. Oral HHV-8 replication among women in Mombasa, Kenya. J Med Virol. 2014; 86(10):1759-65. [PubMed: 24692069]

83. Rohner E, Wyss N, Heg Z, et al. HIV and human herpesvirus 8 co-infection across the globe: Systematic review and meta-analysis. Int J Cancer. 2016; 138(1):45-54. [PubMed: 26175054]

84. Serraino D, Angeletti C, Carrieri MP, et al. Kaposi's sarcoma in transplant and HIV-infected patients: an epidemiologic study in Italy and France. Transplantation. 2005; 80(12):1699-704. [PubMed: 16378064]

85*. Begré L, Rohner E, Mbulaiteye SM, Egger M, Bohlius J. Is human herpesvirus 8 infection more common in men than in women? Systematic review and meta-analysis. Int J Cancer. 2016; 139(4):776-83. This comprehensive meta-analysis seeks to find gender differences of HHV-8 infection from a catchment of multinational studies, especially from SSA regions. The analysis excluded studies focusing on MSM to reduce the confounding of sexual risk factors on HHV-8 acquisition. Interstingly, among studies from SSA regions being male was significantly associated with HHV-8 infection. Further research is needed to elucidate this phenomenon more clearly. [PubMed: 27062038]

86. Castel AD, Young H, Akiwumi AM, et al. Trends in cancer diagnoses and survival among persons with AIDS in a high HIV prevalence urban area. AIDS Care. 2015; 27(7):860-9. [PubMed: 25714364]

87. Calabresi A, Ferraresi A, Festa A, et al. Incidence of AIDS-defining cancers and virus-related and non-virus-related non-AIDS-defining cancers among HIV-infected patients compared with the general population in a large health district of Northern Italy, 1999-2009. HIV Med. 2013; 14(8): 481-90. [PubMed: 23560682]

88. Bohlius J, Valeri F, Maskew M, et al. Kaposi's Sarcoma in HIV-infected patients in South Africa: Multicohort study in the antiretroviral therapy era. Int J Cancer. 2014; 135(11):2644-52. [PubMed: 24729433]

89. Chalya L, Mbunda F, Rambau PF, et al. Kaposi's sarcoma: a 10-year experience with 248 patients at a single tertiary care hospital in Tanzania. BMC Res Notes. 2015; 8:440. [PubMed: 26374100]

90. Koski L, Ngoma T, Mwaiselage J, et al. Changes in the pattern of Kaposi's sarcoma at Ocean Road Cancer Institute in Tanzania (2006-2011). Int J STD AIDS. 2015; 26(7):470-8. [PubMed: 25080290]

91. Cattelan AM, Calabrò ML, De Rossi A, et al. Long-term clinical outcome of AIDS-related Kaposi's sarcoma during highly active antiretroviral therapy. Int J Oncol. 2005; 27(3):779-85. [PubMed: 16077928]

92. Gbabe OF, Okwundu CI, Dedicoat M, Freeman EE. Treatment of severe or progressive Kaposi's sarcoma in HIV-infected adults. Cochrane Database Syst Rev. 2014; (9):CD003256.

93. Asiimwe F, Moore D, Were W, et al. Clinical outcomes of HIV-infected patients with Kaposi's sarcoma receiving nonnucleoside reverse transcriptase inhibitor-based antiretroviral therapy in Uganda. HIV Med. 2012; 13(3):166-71. [PubMed: 22112164] 